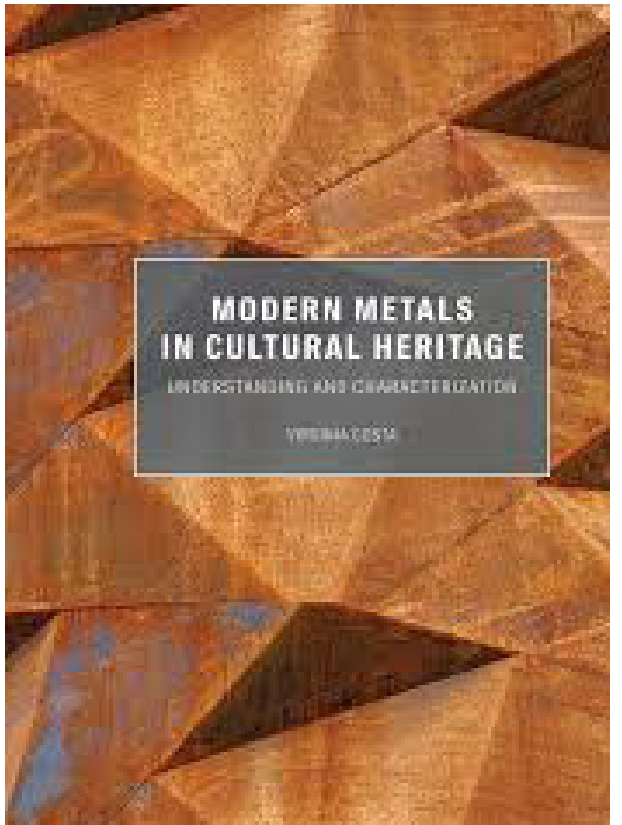

\section{Modern Metals in Cultural Heritage: Understanding and Characterization}

\author{
Virginia Costa \\ Editor: Getty Publications \\ Imprint: Getty Conservation Institute, 2019
}

ISBN: 978-1-60606-605-8

Páginas: 136

Idioma: Inglés

\begin{abstract}
A menudo la información acerca de los procesos de fabricación y degradación de metales, así como la química que rige estos materiales, son manuales técnicos de difícil lectura para aquellos profesionales que no estén familiarizados con una terminología muy académica. El libro Modern Metals in Cultural Heritage es, como bien dice en su introducción, "un puente entre la información técnica publicada y las personas a cargo del patrimonio metálico".
\end{abstract}

La autora, Virginia Costa, es una reconocida especialista en el análisis y conservación de metales que ha trabajado como asesora de multitud de instituciones por todo el mundo. En este libro resume los aspectos más relevantes de las propiedades de los metales y describe los avances técnicos en metalurgia dentro de su contexto histórico.

El uso de materiales en escultura contemporánea ha ido muy a la par con los avances tecnológicos en la historia. En el caso de los materiales metálicos, las nuevas aleaciones diseñadas para automoción, construcción, ingeniería civil o aeroespacial, han servido de base a los artistas para su proceso de creación y la investigación en nuevos materiales en el arte. La salvaguarda de estas obras comienza a estar en riesgo, y en muchos casos el riesgo aumentará con el paso de los años. Comprender el comportamiento de estos materiales es un paso esencial para su correcta conservación; en este aspecto, este libro proporciona información química y metalúrgica para el entendimiento de los procesos de degradación de los metales más utilizados en arte contemporáneo.
El libro se divide en tres partes que a su vez constan de varios capítulos. En la primera parte se hace una revisión de las propiedades químicas del enlace metálico y sus características microestructurales. Por medio de gran cantidad de ilustraciones, describe de forma amena y didáctica las propiedades mecánicas de los metales y los procesos de corrosión. La segunda parte del libro se centra en las aleaciones más utilizadas en arte contemporáneo: aleaciones de aluminio, cobre, titanio, zinc, y hierro (aceros inoxidables y aceros patinables). Describe de manera muy técnica y muy asequible los procesos de fabricación y corrosión, y las propiedades y aplicaciones de las distintas aleaciones. No incluye información sobre técnicas de conservación de obras contemporáneas, aunque finaliza cada sección con una breve bibliografía de intervenciones en estas obras para aquellos que quieran continuar con la lectura. La tercera parte del libro describe los distintos métodos de recubrimientos metálicos y recubrimientos de conversión. Esta última parte resulta muy interesante para todo tipo de profesionales que trabajen con metales ya que resume la información de forma clara y muy bien ilustrada, lo cual no es común en este tipo de literatura. Quizás uno de los aspectos más destacables del libro es que cada capítulo se cierra con un apartado sobre caracterización, con información de gran utilidad y que solo puede proporcionar quien ha acumulado más de cuarenta años de experiencia en el trabajo con metales.

El libro es un manual técnico sobre metalurgia que proporciona información de forma concisa y muy precisa sobre las principales características de los materiales metálicos. Los contenidos están muy bien explicados, 
con gran cantidad de ilustraciones. Su lectura no es sencilla pero sí agradecida. Muy recomendable para aquellos restauradores y conservadores que quieran adentrarse un poco más en la química de los metales y sus aleaciones.

Ana Crespo Ibañez Investigadora en formación (FPI) CENIM-CSIC 